\title{
Experimental and kinetic study of thermal decomposition behaviour of
} phytoremediation derived Pteris vittata

\author{
Authors: Lunbo Duan ${ }^{1,} 2^{*}$, Jian Chen ${ }^{1}$, Ying Jiang ${ }^{2}$, Xiaole Li $^{1}$, Philip \\ Longhurst $^{2}$, Mei Lei ${ }^{3}$
}

1. Key Laboratory of Energy Thermal Conversion and Control, Ministry of Education, School of Energy and Environment, Southeast University, Nanjing, 210096, China;

2. School of Water, Energy and Environment, Cranfield University, Cranfield, Bedfordshire, MK43 OAL, UK

3. Centre for Environmental Remediation, Institute of Geographic Sciences and Natural Resources Research, Chinese Academy of Sciences (CAS), Beijing, 100101, China

${ }^{*}$ Corresponding author: Tel: +86(0)25 8379 0147, E-mail: duanlunbo@seu.edu.cn

\begin{abstract}
Combustion and gasification for biomass to energy conversion is often suggested for the management of residual $P$. vittata from phytoremediation. In this study, the thermal behaviour of $P$. vittata was studied on a thermogravimetric analyser (TG), and the kinetic triplet of biomass sample was further determined for different stages of the thermochemical processes using the Ozawa and KAS methods, subsequently modified by an iterative procedure. Results show that thermal decomposition under combustion condition was complete at a lower temperature of $\sim 500^{\circ} \mathrm{C}$ compared to $\sim 700^{\circ} \mathrm{C}$ for gasification, indicating the both easily complete conversion of $P$. vittata by combustion and gasification. Kinetic study shows that although activation energy for each stage under combustion condition is mostly larger than that under gasification, yet the reaction rate of thermal decomposition of $P$. vittata under combustion condition is still great larger than that under gasification condition. These findings strongly suggest that thermochemical processes offer suitable methods for the volume reduction and energy production of $P$. vittata.
\end{abstract}

KEYWORDS: $P$. vittata, Phytoremediation, Waste biomass, TG, Thermochemical conversion, Kinetic analysis

\section{Introduction}

Globally, arsenic and heavy metals have become the most significant inorganic soil contaminant following intensive mining and associated industrial activates. It is estimated that anthropogenic release of arsenic to soil are 28,400-94,000 tons per year [1]. In China, arsenic pollution is of particularly concern in the mining regions and the vicinity farmland where toxic contaminants are transported from the source points by rainfall or floodwater [2]. The affected regions cover extensive areas and are often in economic deprived rural districts, therefore a cost-effective alternative to conventional remediation approach is required for the treatment and pollution management of these sites. Compared with conventional land remediation 
strategies for heavy metal contaminations, phytoremediation using plants to remove the contaminants from the soil to plant biomass offers significant economic, aesthetic, and technical advantages $[3,4]$.

The success of phytoremediation projects depends on a variety of factors, of which phytoremediation plant selection is key. For phytoremediation of arsenic in particular, there are numerous arsenic hyperaccumulators that have been reported to date, among which the majority belong to the fern Pteris family [5-10] and one particular species, $P$. vittata has been proven successful in many field studies of arsenic phytoremediation [11-13].

However, a key inhibiting factor for a wider implementation of $P$. vittata is the disposal of large quantities of arsenic contaminated plant biomass material throughout the process [14, 15]. It is reported that arsenic concentrations in $P$. vittata can accumulate up to several thousand $\mathrm{mg}$ $\mathrm{kg}^{-1}$ [16], which causes secondary environmental pollution if not properly treated. Thermochemical biomass to energy conversion technologies, i.e. combustion, pyrolysis and gasification, has been proposed as a feasible method to achieve significant volume reduction of phytoremediation derived biomass and bioenergy production [17, 18].

To date, there is little literature record that provides detailed information on the thermal behaviour of phytoremediation biomass, particularly on $P$. vittata. Phytoremediation biomass thermal behaviour study is essential to provide key operational parameters for thermochemical processes optimisation, and further the understanding of bioenergy potential of this particular type of residual biomass. In the development of using phytoremediation as a viable land remediation method and converting biomass residuals from remediation as a bioenergy sources, understanding of the thermal behaviour and reactivity of $P$. vittata is of paramount importance.

Thermogravimetric analysis (TG) is a widely applied technique to study the primary reaction in the decomposition and the thermal behaviours of biomass. TG results, when appropriately interpreted can provide key information of thermochemical reaction stages and kinetics of biomass conversion under a specific thermochemical condition [19], which is particularly important for the burner design and products quality optimisation.

There are a number of mathematical methods proposed to calculate the kinetic parameters based on TG results. These methods can be broadly categorised into model-fitting and iso-conversional methods [20]. Model fitting methods involve fitting different models to temperature curves and simultaneously determining the activation energy $E$ and pre-exponential factor $A$. This normally requires significant efforts of trial-and-error fitting of the curve and can potentially lead to false results, if an inappropriate kinetic model is selected.

Iso-conversional or "model-free" calculation methods calculate activation energy at progressive degrees of conversion $\alpha$ without modelistic assumptions. Iso-conversional methods including Kissinger-Akahira-Sunose (KAS) method [21] and Ozawa method [22, 23] are well established and widely accepted due to their simplicity and avoidance of errors resulted from modelistic assumptions [24]. The errors and inaccuracy associated with these iso-conversional methods are well understood $[25,26]$. During the past decade, an iterative procedure is proposed and often used by researchers to improve the accuracy of results produced from conventional iso-conversional methods [25].

In this study, thermogravimetric analysis (TG) was conducted to study the thermal behaviour of $P$. vittata, and the kinetic triplet of the biomass sample was further determined. To the best 
of the authors' knowledge, this is the first time that the kinetic triplet of $P$. vittata harvested from a phytoremediation field trial has been reported. The thermal behaviour and kinetic information reported in this study will provide valuable information for the follow up experiments using fixed bed and fluidised bed facilities and future scale up thermochemical treatment of phytoremediation residual biomass.

\section{Materials and Methods}

\subsection{Sample Preparation}

$P$. vittata was harvested from a large scale arsenic phytoremediation field trial in South Central China, where the studied site was contaminated with high concentration of arsenic due to flood runoff from nearby mining sites. The arsenic concentrations in biomass and growth soil were determined using Inductively Coupled Plasma - Mass Spectrometry (ICP-MS) following acid digestion [27] and are 237 and $25.3 \mathrm{mg} \mathrm{kg}^{-1}$, respectively. The proximate analysis of the $P$. vittata was performed according to ASTM E871 (moisture content), ASTM D1102 (ash content) and ASTM E872 (volatile) standards. Fixed carbon content was calculated by difference. The ultimate analysis was conducted according to ASTM E777 (carbon, hydrogen), ASTM E778 (nitrogen) and ASTM E775 (sulphur) standards. Oxygen content was also determined by difference. ASTM D2015, E711 standard was used to determine the heating value $[28,29]$. All the above characteristics of the $P$. vittata are listed in Table 1.

Prior to the thermogravimetric study, $P$. vittata was washed with tap water to remove possible adhering soil and dust, followed by rinsing with deionized water. The sample was then dried at $70{ }^{\circ} \mathrm{C}$ in an oven for 48 hours [30]. The dried samples were pulverized by agate mortar and sieved through an 80 mesh sieve to obtain particle sizes of less than $0.2 \mathrm{~mm}$.

Table 1 Proximate and ultimate analysis of $P$. vittata

\begin{tabular}{ll}
\hline Proximate analysis /wt\% (air dry basis) & \\
\hline Moisture & 9.66 \\
Volatiles & 57.46 \\
Fixed carbon & 17.38 \\
Ash & 15.50 \\
Ultimate analysis /wt\% (air dry basis) & \\
\hline Carbon & 39.04 \\
Hydrogen & 4.38 \\
Nitrogen & 1.41 \\
Sulphur & 0.32 \\
Oxygen (by difference) & 29.69 \\
Heating value /MJkg ${ }^{-1}$ (dry basis) & \\
\hline Higher heating value & 18.17 \\
Lower heating value & 16.93 \\
\hline
\end{tabular}

\subsection{Equipment and Method for TG Studies}

A thermogravimetric analyser (Perkin-Elmer Pyris 1, USA) was used to investigate the thermal behaviour of $P$. vittata under combustion and gasification conditions. The combustion tests were carried out using air as carrier gas, whereas $\mathrm{CO}_{2}$ was used for gasification tests. Under both test conditions, the carrier gas flow rate was set at $100 \mathrm{ml} \mathrm{min}^{-1}$. Before starting each test, 
the analyser was purged with carrier gas for a minimum of 1 hour. Approximately $3 \mathrm{mg}$ of the biomass sample was used for each run in this study. Under both combustion and gasification conditions, temperature was raised from room temperature to $800^{\circ} \mathrm{C}$ with a heating rate of 20 , 30,50 and $80{ }^{\circ} \mathrm{C} \mathrm{min}{ }^{-1}$. Each experiment run was conducted in duplicate for data quality assurance.

\subsection{Kinetics Study}

The fundamental isothermal rate equation applied in all kinetic studies in this work is expressed as Eqs. 1 and 2 [31]:

$$
\begin{gathered}
\frac{\mathrm{d} \alpha}{\mathrm{d} T}=k \cdot f(\alpha)=A \cdot f(\alpha) \cdot \exp (-E / \mathrm{R} T) \\
\alpha=\frac{\omega_{1}-\omega_{t}}{\omega_{1}-\omega_{f}}
\end{gathered}
$$

where $\alpha$ is the degree of conversion in \%; $f(\alpha)$ is the conversion function; $k$ is the rate constant of reaction, $\omega_{i}$ is the initial mass of sample; $\omega_{t}$ is the mass of sample at time $t ; \omega_{f}$ is the final mass of sample; $\mathrm{R}$ is the gas constant at $8.314 \mathrm{~J} \mathrm{~K}^{-1} \mathrm{~mol}^{-1} ; T$ is the absolute temperature in Kelvin; $A$ is the pre-exponential factor in $\mathrm{min}^{-1}$, and $E$ is the activation energy in $\mathrm{kJ} \mathrm{mol}^{-1}$. $A, E$ and $f(\alpha)$ are referred to as kinetic triplet. The specific form of conversion function $f(\alpha)$ relies on the actual reaction mechanism and the algebraic expressions of functions commonly applied in solid-state reactions are well documented elsewhere [32].

For non-isothermal thermogravimetric analysis at constant heating rate $\beta\left(\mathrm{K} \mathrm{min}^{-1}\right)=\mathrm{d} T / \mathrm{d} t$, Eq. 1 can be modified into a non-isothermal rate expression Eq. 3 [33]:

$$
\frac{\mathrm{d} \alpha}{\mathrm{d} T}=\frac{A}{\beta} \cdot f(\alpha) \cdot \exp (-E / \mathrm{R} T)
$$

The integral of Eq. 3 can be rearrangement as follows into Eq. 4 and subsequently the integration variable can be redefined as $x=E / \mathrm{R} T$ :

$$
\begin{aligned}
& \mathrm{g}(\alpha)=\int_{0}^{\alpha} \frac{\mathrm{d} \alpha}{f(\alpha)}=\int_{0}^{T} A \cdot \exp (-E / \mathrm{R} T) \mathrm{d} T \\
& \stackrel{x=E / \mathrm{R} T}{\longrightarrow} \frac{A E}{\beta \mathrm{R}} \int_{x}^{\infty} \frac{\exp (-x)}{x^{2}} \mathrm{~d} x=\frac{A E}{\beta \mathrm{R}} p(x)
\end{aligned}
$$

where $g(\alpha)$ is the integral form of the conversion function $f(\alpha)$ and $p(x)$ is the temperature integral presented as $p(x)=\int_{x}^{\infty} \frac{\exp (-x)}{x^{2}} \mathrm{~d} x$. Owning to the fact that $p(x)$ function can't be obtained directly via analytical approaches, to date substantial researches have been carried out to develop computational methods for approximate solutions. Herein the values of activation energy were determined using conventional iso-conversional methods, i.e. Ozawa method (Eq. 5) and KAS method (Eq. 6) [34].

$$
\ln \beta=\ln \frac{0.0048 A E}{\operatorname{Rg}(\alpha)}-1.0516 \frac{E}{\mathrm{R} T}
$$




$$
\ln \frac{\beta}{T^{2}}=\ln \frac{A E}{\mathrm{Rg}(\alpha)}-\frac{E}{\mathrm{R} T}
$$

In Ozawa and KAS methods, linear least-squares method can be applied to plot $\ln \beta$ versus $T^{-1}$ and the plots of $\ln \left(\beta T^{-2}\right)$ versus $T^{-1}$ at various degrees of conversion $\alpha$ (between 0.1- 0.9 , with 0.1 increment was taken in this study), respectively. The slopes of these two plots are therefore used to estimate the values of activation energy derived from Ozawa and KAS methods. However, due to the application of the approximate value of $p(x)$, errors have been proved to occur during the determination of activation energy $[25,26]$. In order to obtain more accurate results closer to 'exact' values of activation energy, an iterative iso-conversional procedure for Ozawa and KAS equations was applied to determine activation energy according to the following equations [35-38]:

$$
\begin{gathered}
\ln \frac{\beta}{H(x)}=\ln \frac{0.0048 A E}{\operatorname{Rg}(\alpha)}-1.0516 \frac{E}{\mathrm{R} T} \\
\ln \frac{\beta}{h(x) T^{2}}=\ln \frac{A E}{\operatorname{Rg}(\alpha)}-\frac{E}{\mathrm{R} T}
\end{gathered}
$$

where $h(x)$ and $H(x)$ are expressed as follows in Eqs. 9 and 10:

$$
\begin{gathered}
h(x)=\frac{x^{4}+18 x^{3}+88 x^{2}+96 x}{x^{4}+20 x^{3}+120 x^{2}+240 x+120} \\
H(x)=\frac{\exp (-x) h(x) / x^{2}}{0.0048 \exp (-1.0516 x)}
\end{gathered}
$$

The iterative procedure performed in this paper is described in detail as follows [25].

First step: Assuming $h(x)=1$ and $H(x)=1$ to evaluate the initial value of the activation energy $E_{1}$. The conventional iso-conversional methods finish the calculation at this step.

Second step: According to the value of activation energy $E_{1}, h(x)$ and $H(x)$ are obtained, and then a new value of activation energy $E_{2}$ is calculated from the plot of $\ln \beta \cdot H^{-1}(x)$ versus $T^{-1}$ or the plot of $\ln \left(\beta\left(h(x) T^{2}\right)^{-1}\right)$ versus $T^{-1}$ on basis of Eq. 7 or 8 .

Third step: Repeating Second step and replacing $E_{1}$ with $E_{2}$. The procedure is not finished until the absolute difference of $\left(E_{i}-E_{i-1}\right)$ is less than a defined small quantity. The last value $E_{i}$ is the exact value of activation energy. Additionally, herein the 'defined small quantity' $(\Delta E)$ used during the iterative calculations was $0.1 \mathrm{~kJ} \mathrm{~mol}^{-1}$.

The error of activation energy obtained from conventional iso-conversional methods, i.e. Ozawa method and KAS method, without performing the iterative procedure is calculated by Eq. 11.

$$
\operatorname{Error}(\%)=100 \cdot \frac{\left|E_{1}-E_{i}\right|}{E_{i}}
$$

where $E_{1}$ is the initial value of the activation energy when assuming $h(x)=1$ and / or $H(x)=1$ in conventional iso-conversional methods. $E_{i}$ is the exact value of activation energy.

Kinetic parameters are strongly dependent on the selection of mechanism functions, herein the degrees of conversion corresponding to multiple heating rates taken from the same 
temperature were put into 35 types of commonly used mechanism functions which is well documented elsewhere [32]. Linear least-square method can be applied to plot of $\ln \beta$ versus $\operatorname{lng}(\alpha)$ defined in Eq. 12, therefore determining the most probable mechanism function [39].

$$
\ln g(\alpha)=\left[\ln \frac{A E}{\mathrm{R}}+\ln \frac{\exp (-x)}{x^{2}}+\ln h(x)\right]-\ln \beta
$$

Since the $g(\alpha)$ function is determined, the value of pre-exponential factor can be calculated from the intercept of the plots of Eq. 6.

\section{RESULTS AND DISCUSSION}

\subsection{Influence of thermal treatment on decomposition of $P$. vittata}

Thermogravimetric (TG) curves in Fig. 1 clearly show that mass of sample starts to decrease immediately as temperature raised. Although thermal decomposition under combustion is complete at a lower temperature of $\sim 500^{\circ} \mathrm{C}$ compared to $\sim 700{ }^{\circ} \mathrm{C}$ for gasification, there is no significant difference in final mass between combustion ( $7.9 \%$ left) and gasification ( $8.1 \%$ left) conditions. This phenomenon may be explained that there was almost no moisture, volatile matter and fixed carbon content existed in the sample and only ash content was remaining after thermal treatments (combustion or gasification). The result suggests that both combustion and gasification can easily realize complete conversion of $P$. vittata.

Differential thermogravimetric (DTG) curves in Fig. 1 indicate that similar to other thermal decomposition study on biomass, there are three distinct mass loss stages during decomposition of $P$. vittata sample, i.e. dehydration, pyrolysis and char conversion [20]. Dehydration stage occurs due to the loss of water present in the sample and external water bounded by the surface tension [40]. For both combustion and gasification conditions, the temperature range for dehydration is between $\sim 30-180{ }^{\circ} \mathrm{C}$, similar to the results observed in previous studies on other biomass samples [41, 42]. Pyrolysis stage of biomass thermal decomposition is caused by volatilisation of hemicellulose, cellulose and part of the lignin contents in the biomass $[43,44]$. Temperature ranges for pyrolysis stage are very approached under combustion and gasification conditions. The temperature ranges under combustion and gasification conditions are between $\sim 180-405{ }^{\circ} \mathrm{C}$ and $\sim 180-425^{\circ} \mathrm{C}$, respectively. The slightly lower temperature range during pyrolysis stage under combustion indicates the presence of oxygen promotes the decomposition of biomass sample [45]. However, char conversion stage of biomass thermal decomposition differs a lot when different thermal treatments are selected. Although char conversion stage under both conditions is partly assigned to the decomposition of the remaining lignin, yet char conversion stage under combustion is also related to the combustion of char residue [46] while under gasification is char gasification [47, 48]. The maximum mass loss rate for this stage under combustion condition is $-0.5 \%{ }^{\circ} \mathrm{C}^{-1}$, which is great larger than that under gasification, as a value of $-0.16 \%{ }^{\circ} \mathrm{C}^{-1}$. Meanwhile, the temperature ranges under combustion and gasification conditions are between $\sim 405-500{ }^{\circ} \mathrm{C}$ and $\sim 425-700{ }^{\circ} \mathrm{C}$, respectively. Both the greatly lower temperature range and significantly larger maximum mass loss rate during char conversion stage under combustion indicate the presence of oxygen promote the decomposition of biomass sample as well. 


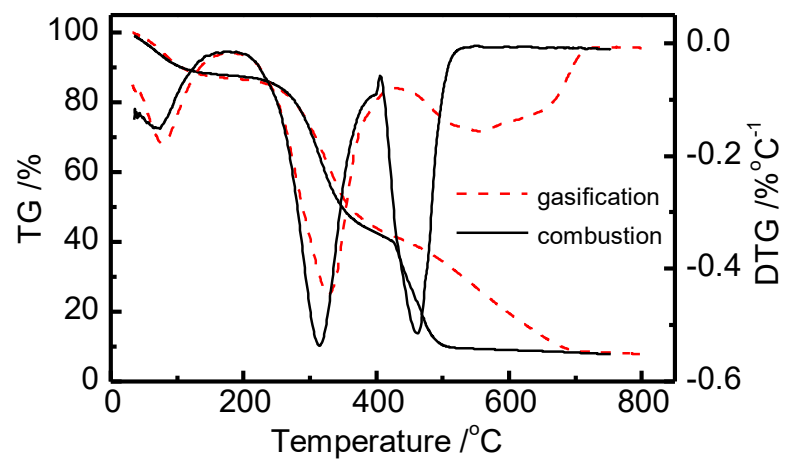

Fig. 1 TG and DTG curves for $P$. vittata in combustion and gasification processes under the heating rate of $50{ }^{\circ} \mathrm{C} \mathrm{min}^{-1}$

\subsection{Influence of heating rate during thermal treatment of $P$. vittata}

Figs. 2 and 3 show the TG curves with a range of heating rates under combustion and gasification conditions, respectively. As shown in Fig. 2 or 3 , most of the curves exhibit the same variation tendency under combustion or gasification condition with the changes of heating rate. Additionally, changing heating rate doesn't lead to any change of final mass under both conditions. The results indicate that heating rate has a negligible effect on final mass of $P$. vittata under thermal treatment conditions, which is coherent with the conclusion obtained by Nie et al. [49].

Figs. 4 and 5 show the DTG curves with a range of heating rates under combustion and gasification conditions, respectively. Just like DTG curves presented in Fig. 1 (under combustion and gasification condition with a heating rate of $50{ }^{\circ} \mathrm{C} \mathrm{min}-1$ ), all the DTG curves at various heating rates can be still separated into three distinct mass loss stages under combustion or gasification condition. Meanwhile, it is interesting to find that heating rate has negligible effect on the previous two stages while significant effect on the char conversion stage. DTG curves of char conversion stage under combustion and gasification conditions exhibit dramatically different variation trend with the change of heating rate. For char conversion stage under combustion condition, an increase of heating rate leads to the shift of DTG curve towards higher temperature and an enhancement in the mass loss peak of sample in DTG curve as a result of the heat transfer limitations [41, 50]. While for char conversion stage under gasification, increasing heating rates leads to an enhancement in the mass loss peak of sample except for the curve of heating rate of $20^{\circ} \mathrm{C} \mathrm{min}-1$ and doesn't cause any shift of DTG curves towards higher temperature, which still need to be further investigated. Despite of the atmosphere, the third stage both consists of two processes, i.e. the decomposition of remaining lignin and the further conversion of generated char residue. Since the lignin decomposition should be very similar, it can be inferred that the differences were caused by the combustion and gasification of char. 


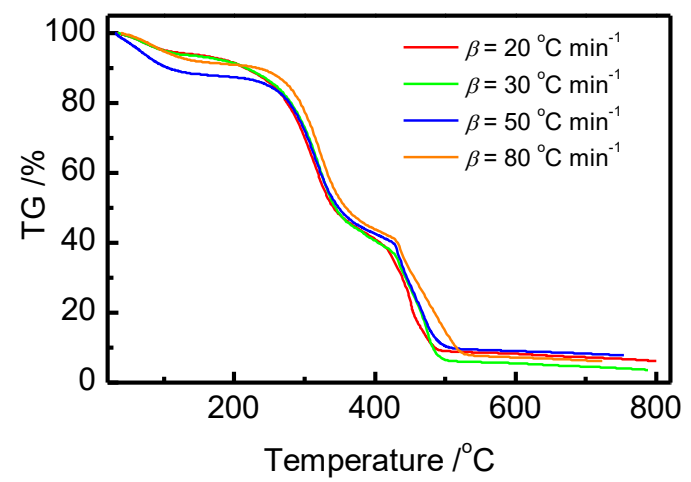

Fig. 2 TG curves of $P$. vittata recorded under combustion condition at four heating rates

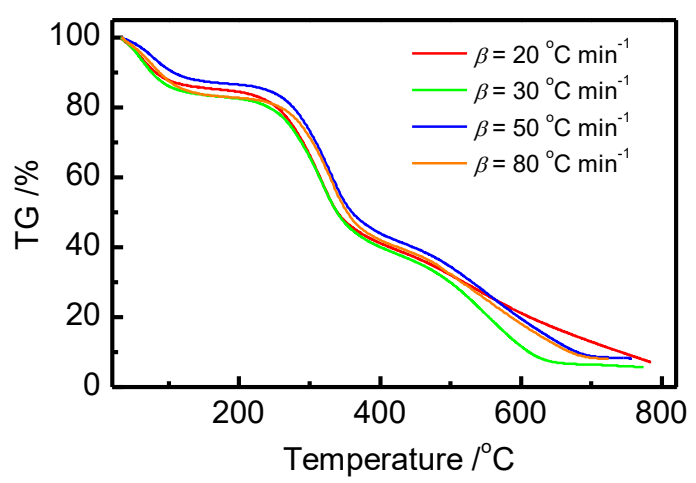

Fig. 3 TG curves of $P$. vittata recorded under gasification condition at four heating rates

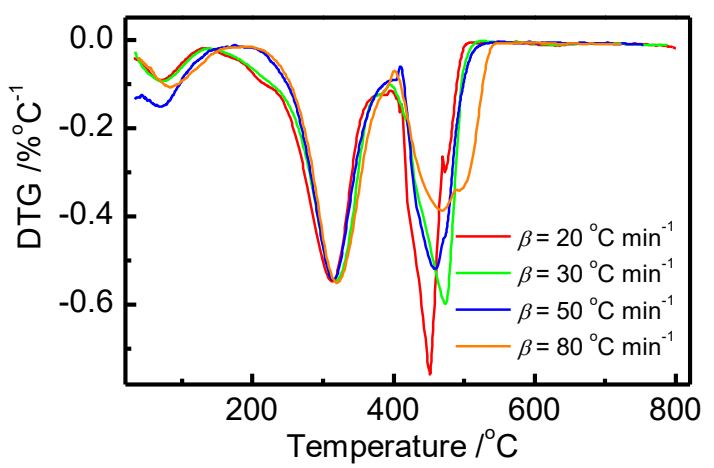

Fig. 4 DTG curves of $P$. vittata recorded under combustion condition at four heating rates

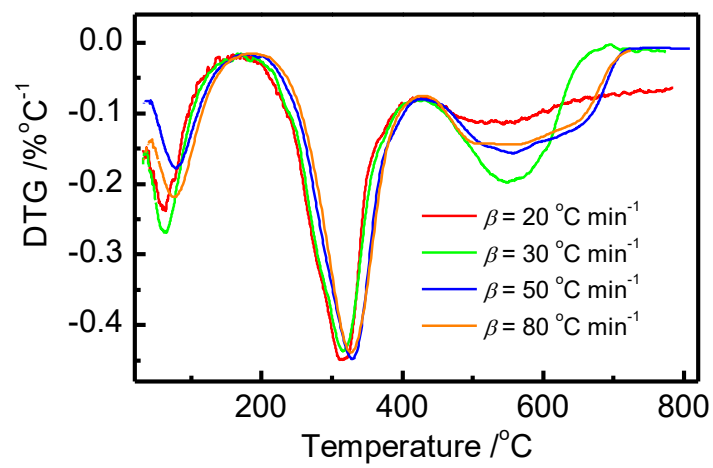

Fig. 5 DTG curves of $P$. vittata recorded under gasification condition at four heating rates 


\subsection{Kinetic analysis}

Kinetic analysis was done to provide key information of thermochemical reaction stages and kinetics of biomass conversion. Since there are three distinct mass loss stages for combustion and gasification and the formation mechanisms for each stage differ greatly, the determinations of kinetic triplet were conducted for each stage instead of whole stage, aiming to obtain more precise parameters. The values of activation energy for each stage determined by Ozawa and KAS method, as well as the error of activation energy obtained from conventional iso-conversional methods without performing the iterative procedure, are tabulated in Tables 2 and 3, respectively.

Table 2 Activation energy $E$ determined from conventional iso-conversional methods (Ozawa method, KAS method) and corresponding iterative iso-conversional procedure for each stage under combustion condition

\begin{tabular}{|c|c|c|c|c|c|c|c|}
\hline & \multirow{3}{*}{$\alpha$} & \multirow{3}{*}{$\begin{array}{l}\text { Ozawa } \\
\text { method } \\
/ \mathrm{kJmol}^{-1}\end{array}$} & \multirow{3}{*}{$\begin{array}{l}\text { Iterative } \\
\text { Ozawa } \\
\text { /kJmol }^{-1}\end{array}$} & \multirow{3}{*}{ Error /\% } & \multirow{3}{*}{$\begin{array}{l}\text { KAS } \\
\text { method } \\
/ \mathrm{kJmol}^{-1}\end{array}$} & Iterative & \multirow{3}{*}{ Error $/ \%$} \\
\hline & & & & & & of $\quad \mathrm{KAS}$ & \\
\hline & & & & & & $/ \mathrm{kJmol}^{-1}$ & \\
\hline & 0.1 & 121.39 & 122.41 & 0.83 & 122.31 & 122.41 & 0.75 \\
\hline & 0.2 & 98.40 & 97.00 & 1.44 & 95.91 & 97.00 & 0.31 \\
\hline & 0.3 & 89.90 & 85.33 & 5.36 & 84.61 & 85.33 & 4.53 \\
\hline \multirow[t]{3}{*}{ Stage } & 0.4 & 76.41 & 76.82 & 0.53 & 74.89 & 76.82 & 1.99 \\
\hline & 0.5 & 72.66 & 70.25 & 3.42 & 68.72 & 70.25 & 1.24 \\
\hline & 0.6 & 67.92 & 65.80 & 3.23 & 64.79 & 65.79 & 1.70 \\
\hline \multirow[t]{7}{*}{ dehydration } & 0.7 & 63.41 & 61.00 & 3.96 & 59.56 & 61.00 & 1.60 \\
\hline & 0.8 & 57.39 & 55.17 & 4.03 & 52.71 & 55.16 & 0.42 \\
\hline & 0.9 & 45.35 & 42.50 & 6.70 & 40.27 & 42.50 & 1.45 \\
\hline & average & 76.98 & 75.14 & 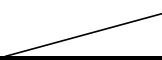 & 73.75 & 75.14 & 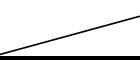 \\
\hline & 0.1 & 64.10 & 60.01 & 6.82 & 58.41 & 60.01 & 2.65 \\
\hline & 0.2 & 112.32 & 109.35 & 2.72 & 109.04 & 109.35 & 0.29 \\
\hline & 0.3 & 159.30 & 158.41 & 0.57 & 158.16 & 158.40 & 0.15 \\
\hline Stage & 0.4 & 207.05 & 203.96 & 1.51 & 203.79 & 203.96 & 0.08 \\
\hline \multirow{2}{*}{ II } & 0.5 & 236.08 & 238.60 & 1.06 & 239.15 & 238.60 & 0.23 \\
\hline & 0.6 & 259.02 & 262.56 & 1.35 & 262.42 & 262.56 & 0.05 \\
\hline \multirow[t]{6}{*}{ pyrolysis } & 0.7 & 267.21 & 275.85 & 3.13 & 276.68 & 275.85 & 0.30 \\
\hline & 0.8 & 284.83 & 284.40 & 0.15 & 281.53 & 284.40 & 1.01 \\
\hline & 0.9 & 337.78 & 344.88 & 2.06 & 342.11 & 344.88 & 0.80 \\
\hline & average & 214.19 & 215.33 & 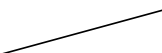 & 214.59 & 215.33 & 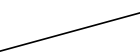 \\
\hline & 0.1 & 312.71 & 318.91 & 1.94 & 320.11 & 318.91 & 0.38 \\
\hline & 0.2 & 344.91 & 350.61 & 1.63 & 354.06 & 350.61 & 0.98 \\
\hline Stage & 0.3 & 354.04 & 364.30 & 2.82 & 364.09 & 364.30 & 0.06 \\
\hline \multirow{2}{*}{ III } & 0.4 & 322.50 & 332.34 & 2.96 & 331.54 & 332.34 & 0.24 \\
\hline & 0.5 & 275.09 & 278.18 & 1.11 & 283.63 & 278.18 & 1.96 \\
\hline char & 0.6 & 225.41 & 226.78 & 0.60 & 227.66 & 226.78 & 0.39 \\
\hline \multirow[t]{3}{*}{ conversion } & 0.7 & 189.89 & 186.03 & 2.07 & 182.66 & 186.03 & 1.81 \\
\hline & 0.8 & 181.66 & 178.84 & 1.58 & 177.73 & 178.83 & 0.62 \\
\hline & 0.9 & 177.57 & 174.37 & 1.84 & 173.97 & 174.37 & 0.23 \\
\hline
\end{tabular}




\begin{tabular}{llll} 
average $\quad 264.87 \quad 267.82+268.38 \quad 267.82$ \\
\hline
\end{tabular}

Table 3 Activation energy $E$ determined from conventional iso-conversional methods (Ozawa method, KAS method) and iterative iso-conversional procedure for each stage under gasification condition

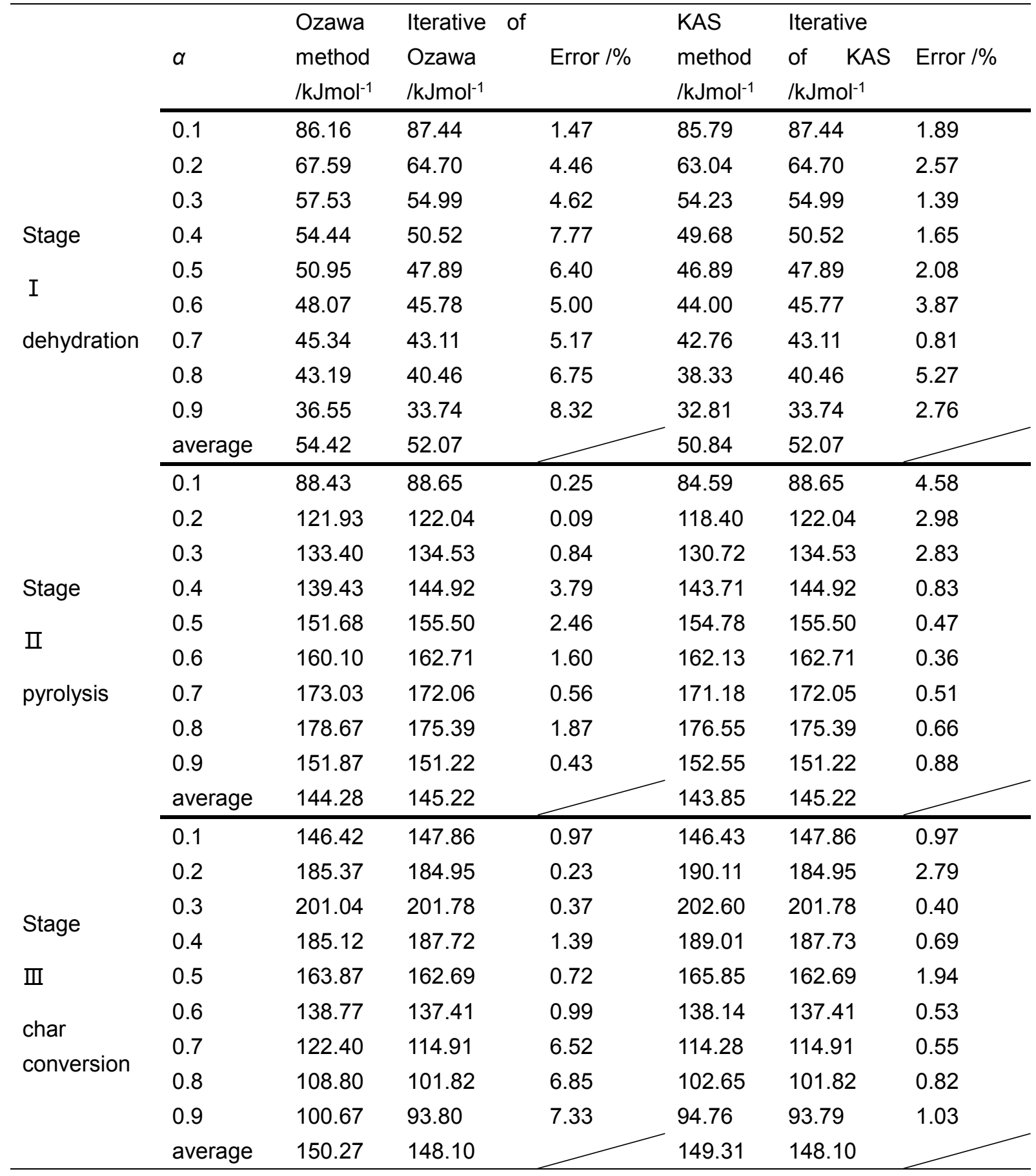

As can be seen from the data in Tables 2 and 3, values of activation energy calculated by Ozawa method, KAS method as well as iterative iso-conversional procedure are very approached and the errors of activation energy associated with conventional iso-conversional methods without performing the iterative procedure are less than $10 \%$, indicating the reliability of the computational results. Moreover, compared with average activation energy for each 
stage under combustion and gasification conditions, it can be interesting to find that activation energy at dehydration stage is the smallest under both conditions, and the activation energy at pyrolysis stage and char conversion stage under gasification condition are very approached while the activation energy at pyrolysis stage is slightly larger than that under combustion condition.

In order to better analyse large amounts of data in Tables 2 and 3, Fig. 6 is designed to exhibit variation tendency of activation energy with degree of conversion for each stage under combustion or gasification condition. Since the great similarities in activation energy determined by iterative iso-conversional procedure for Ozawa and KAS method, values of activation energy determined by iterative iso-conversional procedure for KAS method are chosen as the data for the Fig. 6 .
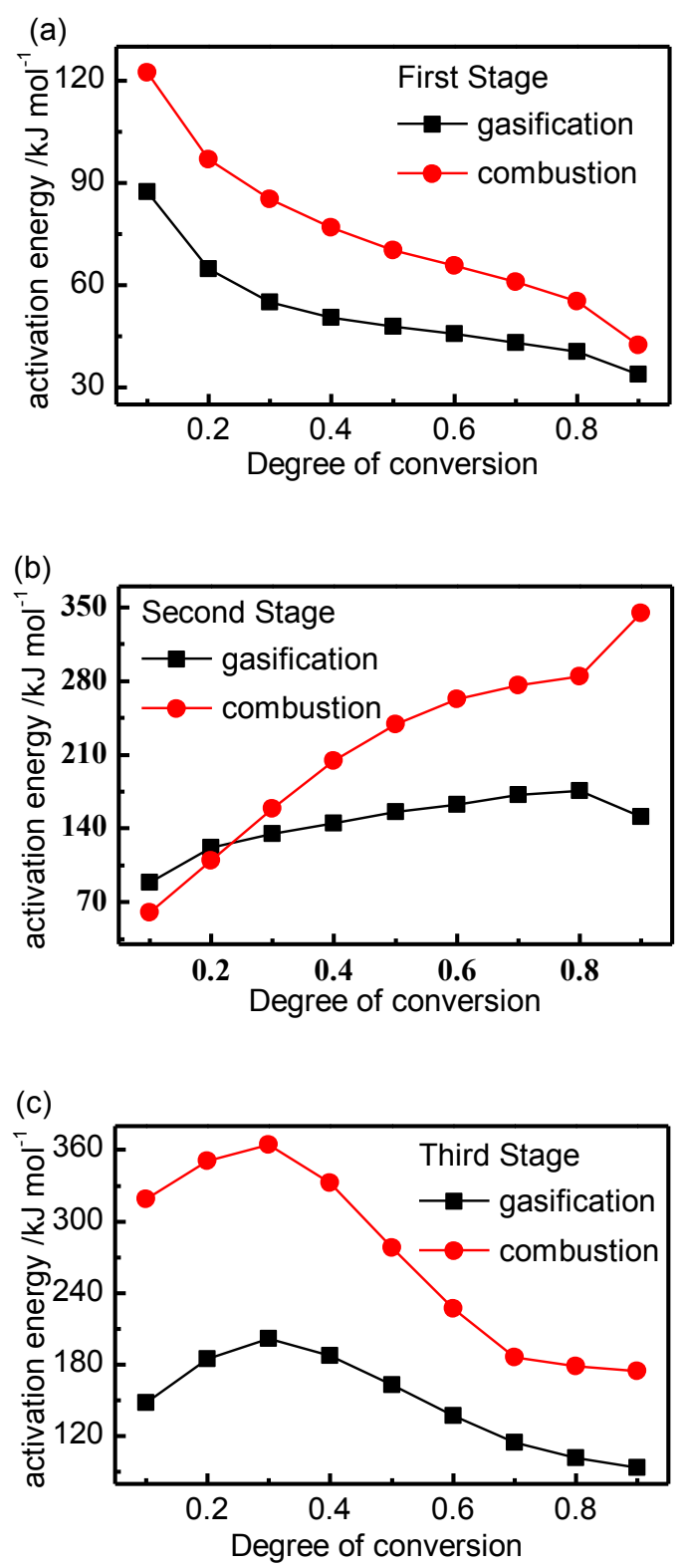

Fig. 6 The variation tendency of activation energy for three stages under combustion and gasification conditions with the increase of degrees of conversion

(a) First stage-dehydration; (b) Second stage-pyrolysis; (c) Third stage-char conversion 
As shown in Fig. 6, it is interesting to find that activation energy under combustion condition is mostly larger than that under gasification condition. The computational result is the same as thermal treatment of charcoal when Boateng et al. [51] investigated thermal conversion of charcoal under combustion and gasification conditions. Moreover, the variation tendency of activation energy with degree of conversion for each stage under combustion or gasification condition shows the same variation. With the increase of degrees of conversion, the values of activation energy under both conditions tend to decrease in the dehydration stage, which is opposite to the variation tendency in the pyrolysis stage. While in the char conversion stage, the values of activation energy tend to increase first and then decrease, reaching a maximum value when degree of conversion is equal to 0.3 .

The most probable mechanism functions for each stage under combustion and gasification conditions, as well as the slope and the correlation coefficient of liner regression $R^{2}$, are tabulated in Table 4 according to Eq. 12. As can be seen in Table 4, the slope and the correlation coefficient of liner regression are very near to -1 and 1 , respectively, indicating the reliability of the $g(\alpha)$ function [36, 52]. For combustion and gasification conditions, distinguishing $\mathrm{g}(\alpha)$ functions were determined for each stage and even at the same stage, $\mathrm{g}(\alpha)$ functions differ significantly when different thermal treatments were applied.

Table 4 The most probable mechanism function $\mathrm{g}(\alpha)$, slope and the correlation coefficient of liner regression $R^{2}$ for each stage under combustion and gasification conditions

\begin{tabular}{lllllll}
\hline & \multicolumn{5}{l}{ combustion process } & \multicolumn{4}{l}{ gasification process } \\
\cline { 2 - 7 } stage & $\mathrm{g}(\alpha)$ & slope & $R^{2}$ & $\mathrm{~g}(\alpha)$ & slope & $R^{2}$ \\
\hline I & {$[-\ln (1-\alpha)]^{2}$} & -0.9957 & 0.9867 & {$\left[(1-\alpha)^{-1 / 3}-1\right]^{2}$} & -1.0088 & 0.9999 \\
II & $\alpha^{2}$ & -1.0164 & 0.9957 & $(1-\alpha)^{-2}-1$ & -0.9871 & 0.9863 \\
III & $1-2 \alpha / 3-(1-\alpha)^{2 / 3}$ & -1.0185 & 0.9973 & $(1-\alpha)^{-1}-1$ & -1.0108 & 0.9467 \\
\hline
\end{tabular}

Furthermore, due to the approximate solution applied in KAS equation is more accurate than that applied in Ozawa equation [52], the values of pre-exponential factor can be estimated according to determined $g(\alpha)$ functions and the slopes of plots of KAS equation. The computational results of pre-exponential factor, as well as the average values of activation energy for each stage under combustion and gasification conditions, are tabulated in Table 5. Although the average values of activation energy under combustion condition are lightly larger than that under gasification condition, yet the values of pre-exponential factor for each stage under combustion condition are several orders of magnitude than that under gasification condition. Hence, considering the combination effect of activation energy and pre-exponential factor in Eq. 1, it is certain that the reaction rate of thermal decomposition of $P$. vittata under combustion condition is still great larger than that under gasification condition, which is consistent with the actual experimental result. 
Table 5 The pre-exponential factor and activation energy for each stage under combustion and gasification conditions

\begin{tabular}{lllll}
\hline & \multicolumn{2}{l}{ Combustion process } & \multicolumn{2}{l}{ Gasification process } \\
\cline { 2 - 5 } stage & $A / \mathrm{s}^{-1}$ & $E / \mathrm{kJ} \mathrm{mol}^{-1}$ & $\mathrm{~A} / \mathrm{s}^{-1}$ & $\mathrm{E} / \mathrm{kJ} \mathrm{mol}^{-1}$ \\
\hline I & $2.53 \times 10^{9}$ & 75.14 & $6.27 \times 10^{2}$ & 52.07 \\
II & $3.32 \times 10^{18}$ & 215.33 & $1.19 \times 10^{7}$ & 145.22 \\
III & $1.17 \times 10^{15}$ & 267.82 & $6.37 \times 10^{3}$ & 148.10 \\
\hline
\end{tabular}

\section{Conclusion}

Thermal behaviour of $P$. vittata was successfully investigated by TG and kinetic triplet was firstly determined according to conventional iso-conversional methods, subsequently modified by an iterative procedure for activation energy. Our results show that:

1) Both combustion and gasification can easily realise complete conversion of $P$. vittata.

2) Although activation energy for each stage under combustion condition is mostly larger than that under gasification, the reaction rate of thermal decomposition of $P$. vittata under combustion condition is still great larger than that under gasification condition.

\section{ACKNOWLEDGEMENT}

The authors wish to thank the financial support from National Natural Science Foundation of China through Grant No. 51206023 and the UK Engineering and Physical Sciences Research Council (EPSRC) through Grant No. EP/K026216/1 (Cleaning Land for Wealth) and a SUPERGEN Bioenergy Hub Small Grant.

\section{REFERENCES}

1. Matschullat J. Arsenic in the geosphere--a review. Sci. Total Environ. 2000;249:297-312.

2. Liu CP, Luo CL, Gao Y, Li FB, Lin LW, Wu CA, Li XD. Arsenic contamination and potential health risk implications at an abandoned tungsten mine, southern China. Environ. Pollut. 2010;158(3):820-6.

3. Xie $Q E$, Yan $X L$, Liao $X Y$, Li $X$. The arsenic hyperaccumulator fern Pteris vittata $L$. Environ. Sci. Technol. 2009;43(22):8488-95.

4. Cunningham SD, Berti WR. Remediation of contaminated soils with green plants: An overview. In Vitro Cellular \& Developmental Biology - Plant. 1993;29(4):207-12.

5. Srivastava M, Ma LQ, Santos JAG. Three new arsenic hyperaccumulating ferns. Sci. Total Environ. 2006;364(1-3):24-31.

6. Zhang W, Cai Y, Tu C, Ma LQ. Arsenic speciation and distribution in an arsenic hyperaccumulating plant. Sci. Total Environ. 2002;300(1-3):167-77.

7. Sinam G, Behera SK, Mishra RK, Sinha S, Mallick S, Khare PB. Comparison of two Ferns (Adiantum Capillus-Veneris Linn. and Microsorium Punctatum (Linn.) Copel) For Their $\mathrm{Cr}$ Accumulation Potential and Antioxidant Responses. Int. J. Phytoremediation. 2012;14(7):629-42.

8. Wang HB, Ye ZH, Shu WS, Li WC, Wong MH, Lan CY. Arsenic uptake and accumulation 
in fern species growing at arsenic-contaminated sites of southern China: Field surveys. Int. J. Phytoremediation. 2006;8(1):1-11.

9. Srivastava M, Ma LQ, Cotruvo JA. Uptake and Distribution of Selenium in Different Fern Species. Int. J. Phytoremediation. 2005;7(1):33-42.

10. Fayiga $A O, M a L Q$, Santos J, Rathinasabapathi B, Stamps B, Littell RC. Effects of arsenic species and concentrations on arsenic accumulation by different fern species in a hydroponic system. Int. J. Phytoremediation. 2005;7(3):231-40.

11. Kertulis-Tartar GM, Ma LQ, Tu C, Chirenje T. Phytoremediation of an arsenic-contaminated site using Pteris vittata L.: a two-year study. Int. J. Phytoremediation. 2006;8(4):311-22.

12. Chen TB, Liao XY, Huang ZC, Lei M, Li WX, Mo LY, An ZZ, Wei CY, Xiao XY, Xie H. Phytoremediation of Arsenic-Contaminated Soil in China. Methods Biotechnol. 2006;23(1):391-402.

13. Wan XM, Lei $M$, Chen TB, Zhou GD, Yang J, Zhou XY, Zhang $X, X u R X$. Phytoremediation potential of Pteris vittata $\mathrm{L}$. under the combined contamination of As and $\mathrm{Pb}$ : Beneficial interaction between $\mathrm{As}$ and $\mathrm{Pb}$. Environ. Sci. Pollut. Res. 2014;21(1):325-36.

14. Dhir B, Srivastava S. Disposal of metal treated Salvinia biomass in soil and its effect on growth and photosynthetic efficiency of wheat. Int. J. Phytoremediation. 2012;14(1):24-34.

15. Jiang $Y$, Lei $M$, Duan LB, Longhurst $P$. Integrating phytoremediation with biomass valorisation and critical element recovery: A UK contaminated land perspective. Biomass and Bioenergy. 2015;83:328-39.

16. Ma LQ, Komar KM, Tu C, Zhang W, Cai Y, Kennelley ED. A fern that hyperaccumulates arsenic. Nature. 2001;409(6820):579-.

17. Šyc $M$, Pohořelý $M$, Jeremiáš $M$, Vosecký $M$, Kameníková $P$, Skoblia $S$, Svoboda $K$, Punčochár $M$. Behavior of heavy metals in steam fluidized bed gasification of contaminated biomass. Energy and Fuels. 2011;25(5):2284-91.

18. Keller C, Ludwig C, Davoli F, Wochele J. Thermal treatment of metal-enriched biomass produced from heavy metal phytoextraction. Environ. Sci. Technol. 2005;39(9):3359-67.

19. Jeguirim M, Dorge S, Trouvé G. Thermogravimetric analysis and emission characteristics of two energy crops in air atmosphere: Arundo donax and Miscanthus giganthus. Bioresour. Technol. 2010;101(2):788-93.

20. Slopiecka K, Bartocci P, Fantozzi F. Thermogravimetric analysis and kinetic study of poplar wood pyrolysis. Appl. Energy. 2012;97:491-7.

21. Magdziarz A, Wilk M. Thermal characteristics of the combustion process of biomass and sewage sludge. J. Therm. Anal. Calorim. 2013;114(2):519-29.

22. Ozawa T. A New Method of Analyzing Thermogravimetric Data. Bull. Chem. Soc. Jpn. 1965;38(11):1881-6.

23. Santos JG, Conceiçõo MM, Trindade MFS, Araújo AS, Fernandes VJ, Souza AG. Kinetic study of dipivaloylmethane by Ozawa method. J. Therm. Anal. Calorim. 2004;75(2):591-7.

24. Opfermann JR, Kaisersberger E, Flammersheim HJ. Model-free analysis of thermoanalytical data-advantages and limitations. Thermochim. Acta. 2002;391(1-2):119-27. 
25. Gao ZM, Nakada M, Amasaki I. A consideration of errors and accuracy in the isoconversional methods. Thermochim. Acta. 2001;369(1-2):137-42.

26. Ortega A, Pérez-Maqueda LA, Criado JM. A new point of view on the evaluation of the temperature integral. Thermochim. Acta. 1996;282-283(SPEC. ISS.):29-34.

27. Zhang X, Houzelot V, Bani A, Morel JL, Echevarria G, Simonnot M-O. Selection and Combustion of Ni-Hyperaccumulators for the Phytomining Process. Int. J. Phytoremediation. 2014;16(10):1058-72.

28. Demirbas A. Combustion characteristics of different biomass fuels. Prog. Energy Combust. Sci. 2004;30(2):219-30.

29. Khalil RA, Mészáros E, Grønli MG, Várhegyi G, Mohai I, Marosvölgyi B, Hustad JE. Thermal analysis of energy crops Part I: The applicability of a macro-thermobalance for biomass studies. J. Anal. Appl. Pyrolysis. 2008;81(1):52-9.

30. Yan XL, Chen TB, Liao XY, Huang ZC, Pan JR, Hu TD, Nie CJ, Xie H. Arsenic transformation and volatilization during incineration of the hyperaccumulator Pteris vittata L. Environ. Sci. Technol. 2008;42(5):1479-84.

31. Kocabaş-Ataklı Z Ö, Okyay-Öner F, Yürüm Y. Combustion characteristics of Turkish hazelnut shell biomass, lignite coal, and their respective blends via thermogravimetric analysis. J. Therm. Anal. Calorim. 2015;119(3):1723-9.

32. Vlaev L, Nedelchev N, Gyurova K, Zagorcheva M. A comparative study of non-isothermal kinetics of decomposition of calcium oxalate monohydrate. J. Anal. Appl. Pyrolysis. 2008;81(2):253-62.

33. Khawam A, Flanagan DR. Solid-state kinetic models: Basics and mathematical fundamentals. J. Phys. Chem. B. 2006;110(35):17315-28.

34. Merad L, Bourson P, Guedra Y, Jochem F, Benyoucef B. Kinetic study of the RTM6/TiO 2 by DSC/TGA for improved hardness of resin. Journal of the Association of Arab Universities for Basic and Applied Sciences. 2012;11(1):37-44.

35. Guan CX, Shen YF, Chen DH. Comparative method to evaluate reliable kinetic triplets of thermal decomposition reactions. J. Therm. Anal. Calorim. 2004;76(1):203-16.

36. L. LQ, Chen DH. Application of ISO-temperature method of multiple rate to kinetic analysis: Dehydration for calcium oxalate monohydrate. J. Therm. Anal. Calorim. 2004;78(1):283-93.

37. Boonchom B. Kinetic and thermodynamic studies of $\mathrm{MgHPO}_{4} \cdot 3 \mathrm{H}_{2} \mathrm{O}$ by non-isothermal decomposition data. J. Therm. Anal. Calorim. 2009;98(3):863-71.

38. He Y, Liao S, Chen Z, Chai Q, Li Y, Su Y, Wu W, Li B. Application of isoconversional calculation procedure to non-isothermal kinetics study: Part II. Thermal decomposition of $\mathrm{NH}_{4} \mathrm{CuPO}_{4} \cdot \mathrm{H}_{2} \mathrm{O}$. J. Therm. Anal. Calorim. 2013;111(1):313-21.

39. Noisong $P$, Danvirutai $C$. Kinetics and Mechanism of Thermal Dehydration of $\mathrm{KMnPO}_{4} \cdot \mathrm{H}_{2} \mathrm{O}$ in a Nitrogen Atmosphere. Ind. Eng. Chem. Res. 2010;49(7):3146-51.

40. Mansaray KG, Ghaly AE. Determination of kinetic parameters of rice husks in oxygen using thermogravimetric analysis. Biomass and Bioenergy. 1999;17(1):19-31.

41. Kumar A, Wang L, Dzenis YA, Jones DD, Hanna MA. Thermogravimetric characterization of corn stover as gasification and pyrolysis feedstock. Biomass and Bioenergy. 2008;32(5):460-7.

42. Tonbul Y. Pyrolysis of pistachio shell as a biomass. J. Therm. Anal. Calorim. 
2008;91(2):641-7.

43. Liu NA, Fan WC, Dobashi R, Huang LS. Kinetic modeling of thermal decomposition of natural cellulosic materials in air atmosphere. J. Anal. Appl. Pyrolysis. 2002;63(2):303-25.

44. Prins MJ, Ptasinski KJ, Janssen FJJG. Torrefaction of wood. Part 1. Weight loss kinetics. J. Anal. Appl. Pyrolysis. 2006;77(1):28-34.

45. Fang MX, Shen DK, Li YX, Yu CJ, Luo ZY, Cen KF. Kinetic study on pyrolysis and combustion of wood under different oxygen concentrations by using TG-FTIR analysis. J. Anal. Appl. Pyrolysis. 2006;77(1):22-7.

46. Bilbao R, Mastral JF, Aldea ME, Ceamanos J. Kinetic study for the thermal decomposition of cellulose and pine sawdust in an air atmosphere. J. Anal. Appl. Pyrolysis. 1997;39(1):53-64.

47. Jindarom $C$, Meeyoo V, Rirksomboon $T$, Rangsunvigit $P$. Thermochemical decomposition of sewage sludge in $\mathrm{CO}_{2}$ and $\mathrm{N}_{2}$ atmosphere. Chemosphere. 2007;67(8):1477-84.

48. Kim YJ, Kim MI, Yun CH, Chang JY, Park CR, Inagaki M. Comparative study of carbon dioxide and nitrogen atmospheric effects on the chemical structure changes during pyrolysis of phenol-formaldehyde spheres. J. Colloid Interface Sci. 2004;274(2):555-62.

49. Nie CJ, Yan XL, Chen TB, Liao XY, Pan JR, Zhou BL, Wu LS. Pyrolysis characteristic of arsenic hyperaccumulators and its relation to arsenic content. Acta Scientiae Circumstantiae. 2003; 27(5):721-6.

50. Quan C, Li AM, Gao NB. Thermogravimetric analysis and kinetic study on large particles of printed circuit board wastes. Waste Manag. 2009;29(8):2353-60.

51. Boateng AA. Characterization and Thermal Conversion of Charcoal Derived from Fluidized-Bed Fast Pyrolysis Oil Production of Switchgrass. Ind. Eng. Chem. Res. 2007;46(26):8857-62.

52. Kullyakool S, Danvirutai $\mathrm{C}$, Siriwong K, Noisong P. Determination of kinetic triplet of the synthesized $\mathrm{Ni}_{3}\left(\mathrm{PO}_{4}\right)_{2} \cdot 8 \mathrm{H}_{2} \mathrm{O}$ by non-isothermal and isothermal kinetic methods. J. Therm. Anal. Calorim. 2014;115(2):1497-507. 